\title{
VICTORIA UNIVERSITY OF WELLINGTON
}

Te Whare Wananga o te Upoko o te Ika a Maui

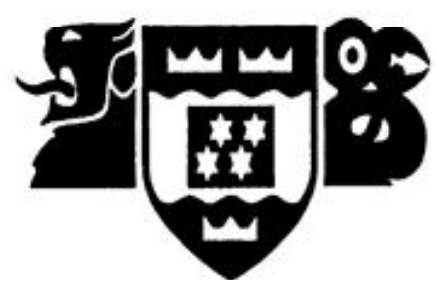

An investigation on the constraints to

telework implementation in New Zealand businesses

\section{MMIM 592}

By

Minh Huu Pham

ID: 300165392

Supervisor: Tony Hooper

Submitted to the School of Information Management,

Victoria University of Wellington

in partial fulfillment of the requirements for the degree of

Master of Information Management

04 June 2010 


\section{Preface}

This report is not confidential.

I would firstly like to thank my supervisor, Tony Hooper for his guidance and support during this study. Thank you also to Dr. Brian Harmer for his idea and his help during the data collection phase.

I would like to thank NZCS, TUANZ, Sustain Business Network and IPENZ - the organizations who helped me forward invitation to their members. Many thanks to all participants who took part in the survey; without them, this study could not be done.

I would like to express my gratitude to Chris Sander and Hamish Clayton for assistance with checking the text for grammatical and other related errors.

Last, but not least, I would like to thank my family for tremendous supports they have given me. My mom and dad have endlessly encouraged and supported me. My brother has inspired me with his advices. Also thanks to Nhung, my closest friend despite distance who was actively involved in the data collection phase.

I certify that except as noted above, the Report is my own work and all references are accurately reported.

Minh Huu Pham

June 04, 2010 


\section{Table of Content}

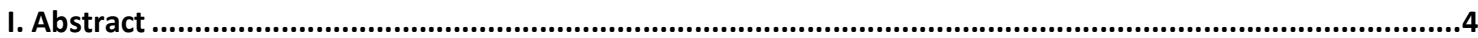

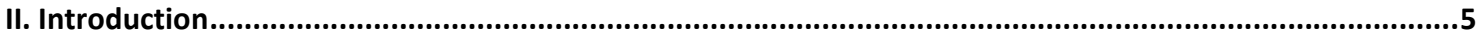

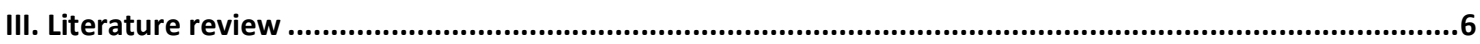

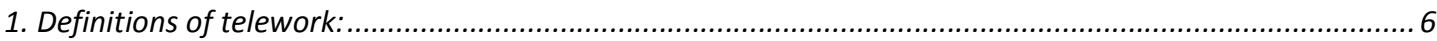

2. Technology adoption and implementation in organizations ........................................................ 7

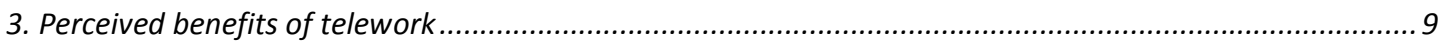

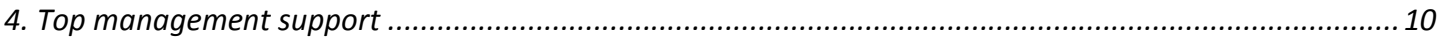

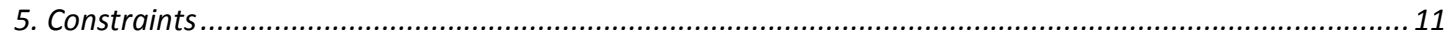

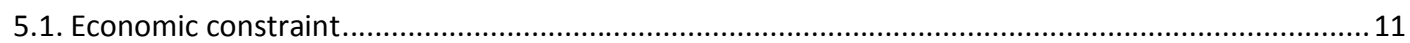

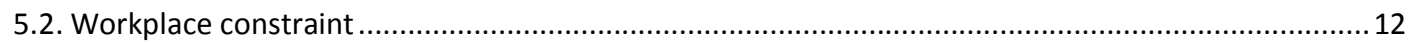

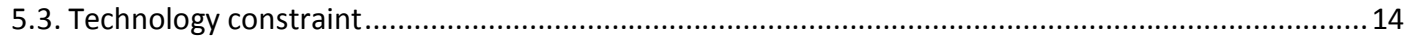

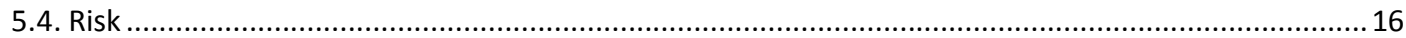

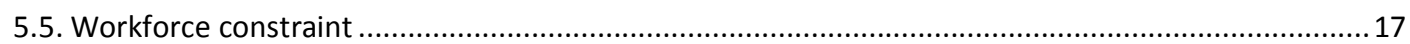

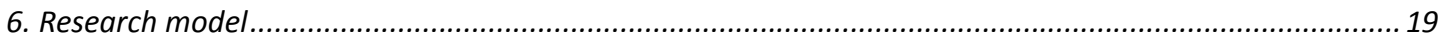

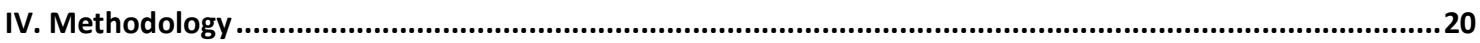

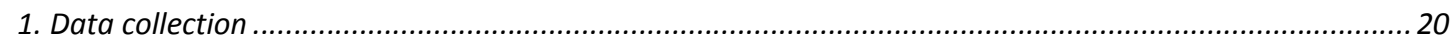

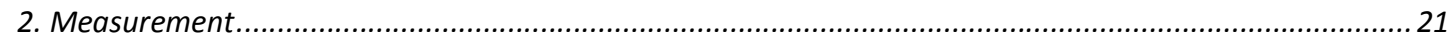

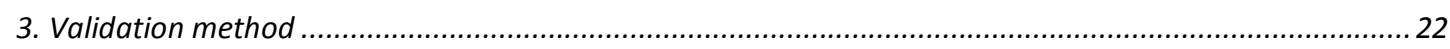

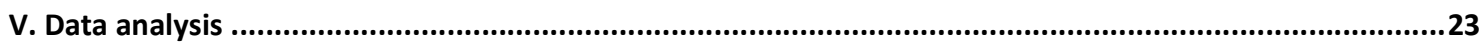

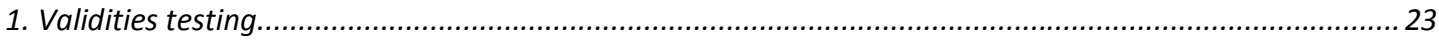

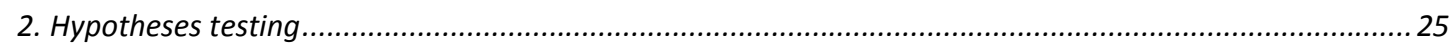

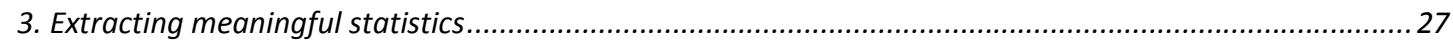

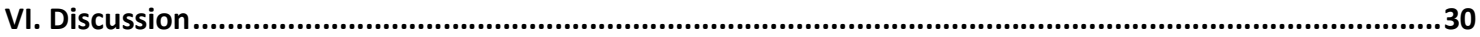

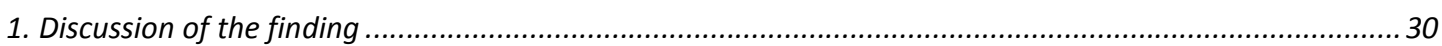

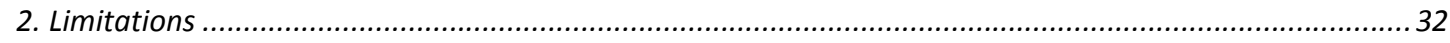

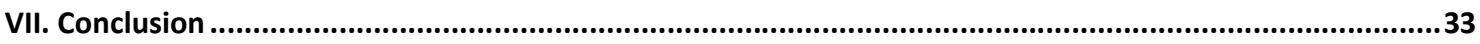




\section{List of Figures}

Figure 1. Research model of constraints to telework implementation ...............................................20

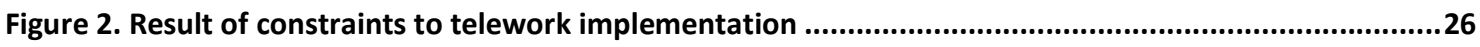

\section{List of Tables}

Table 1. The TOC five-step focusing process (adapted from Reid \& Shoemaker, 2006, p. 64)........................8

Table 2. Tasks carried out by teleworkers (Tremblay, 2002, p. 161) ...................................................17

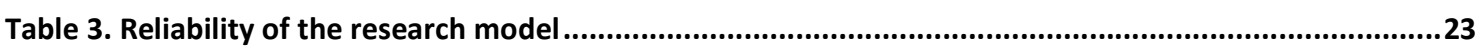

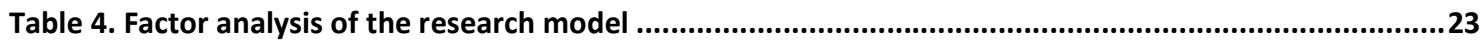

Table 5. Result of proportion of workforces involved in teleworking......................................................24

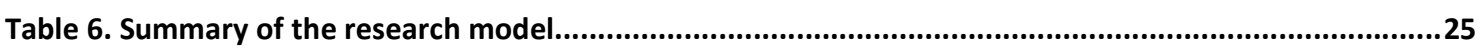

Table 7. Impacts of each constraint on the proportion of telework implementation ....................................25

Table 8. Main constraints of telework specified by participants ...............................................................26

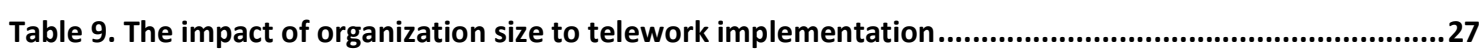

Table 10. Relationship between the fear of losing people and the size of organization ..............................22

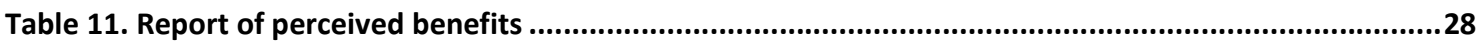

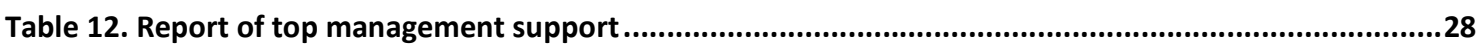

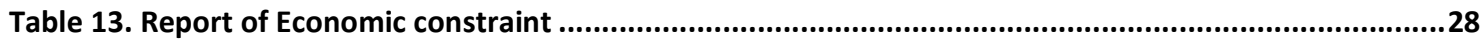

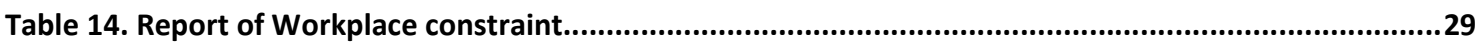

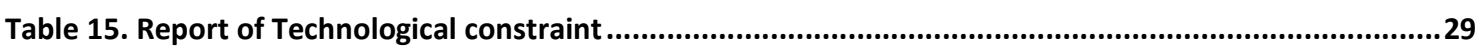

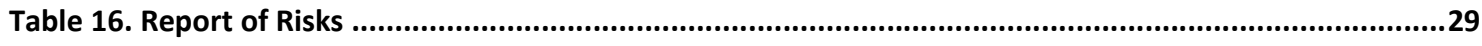

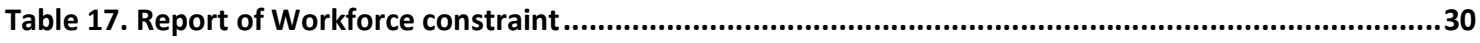




\section{Abstract}

Telework has many potential benefits for both employers and employees, and has been explored extensively in past and present research. However, the adoption rates of telework is much lower than expected. Organizations in general as well as in New Zealand are reluctant to implement it on a grand scale. The purpose of this study is to find the answer for this phenomenon.

This study takes an approach based on the Theory of Constraints to discover one of the main constraints to telework implementation. Constraints were explored across seven factors: perceived benefit, top management support, economic constraint, workplace constraint, technological constraint, risks and workforce constraint. Data were collected from members of four professional associations in New Zealand that specialized in the ICT and commerce fields.

The results of this study indicated that lack of top management support is the main constraint to telework implementation in New Zealand businesses. The author suggests that managers should pay more attention to top management support, workforce issues and culture change for a successful telework program. Future research should seek the opinions of non-adopters; explore workforce constraints; and use a data collection method that can identify participants' demographics. 


\section{Introduction}

The development of technology has significant impacts on every aspect of human life, how people live, work and do business. For example, mobile technologies were first developed as customer products, and then were quickly adopted for restructuring business process and for organizational benefit (Kakihara \& Sorensen, 2004). Technology benefits organizations as it brings mobility, increases productivity and allows workers to leave the office and spend more time at home (Gendreau, 2007). The concept of the workplace is extended beyond the physical boundary; people interact with customers outside of their workplace, but still in the organizational framework (Corso, Giacobbe, Martini, \& Pellegrini, 2006).

Telework or telecommuting is an example of how technology affects organizations and how people work. In 1990s, telecommuting emerged as an opportunity to improve productivity and effectiveness enabled by advanced Information Technology (IT) infrastructures (Watad $\&$ Will, 2003). The increase in availability of expertise in Information and cCommunication Technology (ICT) has facilitated the adoption of telecommuting (Baker, Avery, \& Crawford, 2006), or we can say that the development of IT is a driver of telework.

Telework is a working arrangement which allows employees to work at a location other than a central office, but being linked by means of IT (Watad \& Will, 2003). Rasmussen and Corbett (2008) emphasized that by using technology, employees can cut down the time and cost of commuting. The three terms "telecommuting", "telework" and "virtual office" are used interchangeably and refer to the phenomenon that workers are given work and can report from home or in a telework center rather than a central office location (Siha \& Monroe, 2006). There are some arguments about the standard of telework; such as whether workers that spend most of their time out of the office due to the nature of their jobs be considered teleworkers. However, we can consider telecommuters as employees who use ICT to fill the gap of not being present in their office.

The expected shift from working in the office to telecommuting since 1980s has not occurred (Baker et al., 2006). Siha and Monroe (2006) reported the reluctance of organizations to deploy telework on a grand scale. They suggested that future research should focus on why the growth of telecommuting has progressed so slowly; Do barriers differ from country to country? A study in 2007 showed that less than $20 \%$ of organizations in New Zealand use telework, the lowest proportion compared to any other investigated country (Rasmussen \& 
Corbett, 2008). The authors suggested that there must be an extremely strong reason to avoid such a highly beneficial scheme.

Arising from the contradiction between the benefits of telework and the low rate of adoption in organizations, especially in New Zealand organizations, this research aims to explore that issue by identifying the main constraints of telework adoption in the decision making stage.

In the absence of empirical research, findings from this study will help managers and strategy makers to deploy telework programs in their organizations. It will also contribute to the literature on organizational issues in telework.

Because of time limitations, the author seeks to explore only why organizations are reluctant to use telework in the New Zealand context. A quantitative methodology was used to explore pre-defined constraints on telework programs in New Zealand organizations.

\section{Literature review}

\section{Definitions of telework:}

Rasmussen and Corbett define teleworking as "employee being able to work away from the office (often from home) with a connection to the office via some kind of telecommunication" (2008, p. 21). Technology solution for teleworking includes Internet access, telephone, facsimile, SMS messaging, or even email. Telework can be done from home (home-based), in satellite-based offices, or in any locations other than central office that are connected by a technological means (Rasmussen \& Corbett, 2008). The broader definition of any location other than office makes it hard to provide a clear standard for telework. Indeed, Siha and Monroe (2006) suggested that there hasn't existed a standard definition for telework: time working away from the office, an alternative location other than home, and whether mobile workforces who spend most of their time out of office should be considered telecommuters.

There are some studies that focus only on home-based telecommuting such as those of Baker et al. (2006), Fynes-Clinton (2005) and Tremblay (2002). Schweitzer and Duxbury (2006) classified home-based teleworkers into substitutors (work at home full time), supplementors (work overtime at home) and self-employed (business is based in employee's home). Even with this narrow approach, there are some debates regarding whether or not self-employed 
workers are really teleworkers. In this study, the concept of telework will emphasize two issues: working away from the central office, and the use of ICT to connect with the office.

There are some other classifications of telework, such as full-time or part-time, formal or informal telework. Informal teleworking allows employees to do telework without any formal document or agreement. This type of teleworking is more common, and is used as a temporary means to provide flexibility (Rasmussen \& Corbett, 2008). Part-time telework means workers still need to be present in their office, and can do telework in or over working hours.

\section{Technology adoption and implementation in organizations}

Technology adoption, especially IT adoption in an organization is a popular field of research, with many case studies, empirical research, and a strong theoretical background to support it. IT adoption and implementation is divided into different stages, with different associated issues and challenges, including the organizational, human, technological and managerial issues (Munkvold, 1999). The adoption of IT in turn drives the change in business process in workplace, workforce and business structure (Lee, Chu, \& Tseng, 2009).

Organizational innovation, market pressure and competitive intensity are the common factors that positively affect information technology adoption (Lee et al., 2009). According to Veiga, Floyd and Dechant (2001), culture (the level of individualism/collectivism, uncertainty avoidance, time orientation and power distance) is also a strong factor that influences the IT implementation and acceptance in an organization. The authors suggested that people from countries relatively low in power distance and uncertainty avoidance such as UK, USA, and New Zealand are more likely to accept new IT and have a greater need for participation in its development. While we can learn from different case studies, "personal factors, characteristics of innovation and context will shape the ultimate decision and persistence with a technology" (Straub, 2009).

The Technology Acceptance Model and Unified Theory of Acceptance and Use of Technology Model have been used frequently in technology adoption and implementation research. However, these two models focus on the use and acceptance of technology by individuals who often do not have a choice whether or not to adopt the technology (Straub, 2009). These models are useful in exploring the acceptance of the technology implementation projects, but have little use in the adoption decision making process which involves a small 
number of managers of high positions. In this study, another theory is needed, which can address the problem in the decision-making stage and gain acceptance from top management. The Theory of Constraints (TOC) was introduced in a series of Eli Goldratt's books in the mid-1980s (Rahman, 1998). This theory considers constraint as an opportunity for improvement. It provides five-focusing-steps to address constraints and the thinking process to deal with those constraints. The main idea of TOC is that management attention should be focused on the few constraints that prevent the organization from achieving its goals (Geri \& Ahituv, 2008). There are three interrelated assertions of TOC (Reid \& Shoemaker, 2006):

1. Every system has a goal and a set of necessary conditions that must be satisfied if that goal is to be achieved

2. The overall system performance is more than just the sum of its component performances

3. Very few factors or constraints limit a system's performance at any given time.

TOC proposes five focusing steps to improve system performance, starting with identifying constraints. By assuming that the goal of an organization is to make money, TOC suggests that organization's performance is measured by two main sets of measurements: financial and operational measurement, these could be the main constraints (Rahman, 1998).

Table 1. The TOC five-step focusing process (adapted from Reid \& Shoemaker, 2006, p. 64).

\begin{tabular}{|l|l|}
\hline \multicolumn{1}{|c|}{ TOC five-step focusing process } & \multicolumn{1}{c|}{ Explanation } \\
\hline Identify the constraint & $\begin{array}{l}\text { Determine the system activity whose capacity is less than the demand } \\
\text { placed in it } \\
\text { Maximize the efficiency of the constraint activity in its existing } \\
\text { system configuration } \\
\text { Synchronize the operation of all other system components with the } \\
\text { constraint activity } \\
\text { Increase the capacity of the constraint activity to eliminate it as a } \\
\text { constraint } \\
\text { Revisit all changes to ensure that they still support current system } \\
\text { Return to step } 1 \text { but prevent inertia }\end{array}$ \\
\hline
\end{tabular}

After identifying the main constraints, the TOC's thinking process is used to make three generic decisions: (1) decide what to change; (2) decide what to change to; and (3) decide how to change (Rahman, 1998).

The TOC has been implemented successfully in manufacturing organizations, as well as in non-manufacturing industries such as financial institutions, enterprise software, health services, public sector and education to improve system performance (Geri \& Ahituv, 2008). 
It addresses many of the traditional concepts of operations management from a more unified perspective, and has the potential to be a unified theory for operational management (Gupta \& Boyd, 2008). However, TOC is an immature methodology, which lacks empirical testing and is viewed skeptically by many researchers (Gupta \& Boyd, 2008). Gupta and Boyd (2008) also suggest that the results of TOC are feasible but not always optimal. However, how would we know if one solution is optimal or not? Watson, Blackstone, and Gardiner (2007) commented that the thinking process of TOC is considered hard to implement and is not user friendly.

Despite these criticisms, TOC is extremely useful in this situation. We consider telework program a system whose goals are to let employees work away from the central office and to achieve benefits such as increasing productivity, saving real estate cost. This system must have at least one constraint; otherwise an organization can be turned into a telework-based organization, and no employees need to go to the office. According to Watson et al. (2007), TOC is useful in addressing the problems, sustaining recent gain and obtaining top management support. Managers should pay attention to only a few constraints that have significant impacts on system performance and hinder the process of achieving its goal. Financial and operational issues are the two main constraints of most systems in Theory of Constraint (Watson et al., 2007). The purpose of this study is to identify constraints of the system, which is the first step in the TOC five-step focusing process as showed in Table 1.

\section{Perceived benefits of telework}

Telework has many potential benefits for employees, employers, environment and society. This section will mainly address the potential benefit for employers, which may appeal to decision makers in organizations. According to Crandall and Gao (2005), organizational benefits of telecommuting are productivity increment, operating cost reduction, a new recruitment option and the ability to adapt to the virtual organization.

Crandall and Gao (2005) found some evidence that telecommuting increases productivity for instance telecommuting salespersons at AT\&T increased sales by $20 \%$ to $40 \%$, while telecommuting managers at AT\&T increase productivity by $8 \%$ to $29 \%$. Rasmussen and Corbett (2008) give evidence that $82 \%$ of participant organizations have positive productivity gains when adopting teleworking arrangements. However, Ruth and Chaudhry (2008) consider telework a productivity paradox because there are so few workers involved in telework. Moreover, the productivity gains may be influenced by factors such as a selection 
of better workers for telework, the unreliability of self-reported gains and an inability to separate overall management improvement and improvement due to telework.

According to Rasmussen and Corbett (2008), telework lowers operating costs as a result of space saving, productivity improving, and energy consumption reduction. Two good examples are described by Mello (2007), who reports that Sun Microsystems saved \$69 million in real estate costs in 2005, and AT\&T have saved \$25 million annually since 1992 by implementing a telework program.

The study of Siha and Monroe (2006) reviewed literature about telework and found many possible benefits of telework for organizations, employees as well as environment. Adoption of telework in competitors is found to be the main motivator for organizations to initiate a telework program. They also mention the benefit of telework in recruitment and employee retention. Tremblay (2002) has explored characteristics of teleworkers in Quebec, Canada and found that more than half of them are very satisfied with the telework arrangement.

According to Mello (2007), telework brings flexibility that allows employees to manage working time at their convenience. It also allows individuals to remain employed when they need to be reallocated for personal or family reasons, and therefore contributes significantly to the employee retention options. The empirical research of Schweitzer and Duxbury (2006) which explored characteristics of employers and employees involved in telework suggested that organizations that support the use of telework will be more able to attract and retain knowledge workers.

Rasmussen and Corbett (2008) argue that though few researchers disagree with the positive advantages of teleworking, there is a skeptical view of whether these positive outcomes really occur. This skeptical view can be an important obstacle that hinders the adoption decision of telework in an organization.

Using the information outlined above gives rise to the first of the hypotheses that will be tested in this research:

H1: The perceived benefit of telework positively influences the adoption and implementation of telework.

\section{Top management support}

The support from top management is crucial in any technology implementation program. A large amount of literature emphasized top management support as one of the main success 
factors of telework implementation, followed by comprehensive training and reliable technical solutions (Siha \& Monroe, 2006). According to Ruppe and Howard (1998), the existence of champions and top management support are important in the adoption and diffusion of telework. These factors are important across many different innovations, while other variables such as communication media, training, and security may take effect only in some innovations, or some phases of innovation. The authors suggested that the champions of a telework program should obtain top management support in order to reduce barriers to telework diffusion in an organization.

Since there are not many organizations using telework, the lesson learned about telework implementation is limited. The foremost lesson learned from a successful telework program in US Patent and Trademark Office was the existence of a strong champion from top leadership (Meadows, 2007). A champion needs to understand the value and benefits of telework, and spreads it to all employees as well as managers in the organization. This then gives rise to the second hypothesis that will be tested in this study:

H2: Top management support positively affects the adoption and implementation of a telework.

\section{Constraints}

In the Theory of Constraint, constraints are anything that limits a system from achieving higher performance (Rahman, 1998). Each system in general has more managerial constraints than physical constraints. In case of telework, extensive literature review showed five main constraints in an organization, including (i) economic constraint; (ii) workplace constraint; (iii) technology constraint; (iv) risk; and (v) workforce constraint. The following section will discuss these constraints in more detail, but understanding constraint gives rise to the third hypothesis:

\section{H3: Constraints negatively affect the adoption and implementation of telework program}

\subsection{Economic constraint}

Definition: For the purposes of this study, economic constraint is defined as the financial barrier when implementing telework program

The cost of a telework program does not only involve the technology cost. According to D'Arruda (2001), there are direct and indirect cost associated with telecommuting for employers. Direct cost includes: (1) telecommunication hardware, software, and operating 
costs; (2) additional telecommuting specific training; (3) computer hardware; (4) moving and installing equipment in home-based sites; (5) increased administrative expense including changes to administrative systems, cost of system integration and coordination; and (6) readiness for IT infrastructure. Indirect cost involves (1) union resistance; (2) setting precedents; and (3) increased energy consumption because of the shift from central office to many homes and using smaller telework facilities.

According to Mello (2007), hardware, software and telecommunication facilities for telework can be a significant expense, so an employer has to consider how much of the cost can be employer-assumed and/or subsidized. Especially if a company has many teleworkers, then the technology cost can be considerable. In the context of New Zealand, Rasmussen and Corbett (2008) suggested that small businesses do not have enough resources to invest in productivity enhancing technology. However, Meadows (2007) suggested that the technology cost for telework can be expensive, but still a small expense compared to real estate.

Joice (2007) summarized the study of Telework Technology Cost (2006) by US General Services Administration (GSA) with a general finding that technology costs are invisible to senior executives. Telework programs can use existing IT infrastructure, reuse equipment from office and from home; technology investment can be shared with other programs, and more importantly can be transformed into benefits that are even larger for the entire organization. The Joice's study showed that a technology investment can be turned into

telework financial benefits and benefits for other programs with the return on investment of up to 1500 percent in three years.

In conclusion, though the cost for a telework program can be quite cumbersome in some situations, it is still not a big concern for the employer. We can expect that it is not the biggest constraint for telework adoption and implementation.

\subsection{Workplace constraint}

Definition: For the purposes of this study, workplace issues include (1) size of organizations; (2) organizational culture; (3) relationships between employees and managers or coworkers; and (4) attitude of managers.

Rasmussen and Corbett (2008) find some explanations for the low adoption of telework in New Zealand, including the prevalence of small businesses: losing one person out of the office can be a big deal. However, the authors do not explain why losing one person in a 
small office is a problem. The research of Tremblay (2002) found that a quarter of teleworkers in Quebec are employed in firms with less than ten employees; and a half of them are self-employed. Though larger companies still take a higher proportion in telework adoption, there is not enough evidence to say that size of organizations is a constraint to telework.

The research of Watad and Will (2003) about middle manager's perception when implementing a telework program showed that culture change is the most important obstacle. Culture cannot be changed just by implementing an IT project, but must be improved regularly by training and informing employees about benefit of the new project. Siha and Monroe (2006) found many articles dealing with corporate culture in telework issues. Corporate culture affects employee's continuous interaction and face-to-face communication, and affects the level of employees trust. However, they also found empirical evidence, which suggested that telework has no significant impact on the method or frequency of communication, managers will adapt to it (Siha \& Monroe, 2006). They conclude that lack of employees trust is a primary barrier telecommuting adoption and diffusion.

When team members become remote, it is hard to keep the sense of teamwork (Crandall \& Gao, 2005). According to Mello (2007), there is no empirical research on how virtual work might affect work relationships and outcomes. However, telework can often be seen as an individual contribution arrangement which fragments collectivity.

Managing a worker who is only occasionally in sight can be a challenge. Managers must manage by task completion rather than monitoring and observing progress (Ruth \& Chaudhry, 2008). Crandall and Gao (2005) found that managers are afraid of losing direct control over the telecommuters, and find it hard to measure their performance, create a sense of team-work, and ensure employees' safety and health. According to Mello (2007), managers are not only concerned about how to measure employee's performance, but they also find it hard to provide meaningful feedback. Rasmussen and Corbett (2008) introduced the notion of "presenteeism", the idea that managers appreciated employees being at work more than working efficiently, which can be seen where a direct management style rules.

The study of Watad and Will (2003) found that 81 percent of managers interact with their employees on a daily basis either very frequently or frequently. To keep stability, continuity and efficiency of manager's daily work, telework technology must enable high-interaction communication. The finding of this research that middle managers prefer one time radical 
change rather than a high level of variation in their daily work implies that full time telecommuting is the middle managers' preference. This has a serious implication on how telework program should be designed and implemented.

Fynes-Clinton (2005) reported results of a study carried out in Australia and New Zealand. The study suggested that managers tend to lack trust in telecommuters. Half of the managers surveyed believe that telecommuters do not work as hard. The survey of attitudes to teleworking in Australia and New Zealand found that managers do not trust their employees enough to allow them to undertake telework (Rasmussen \& Corbett, 2008). Organizations are also reluctant to use telework as a prominent corporate wide strategy (Siha \& Monroe, 2006), and do not wish to broadcast teleworking opportunities (Rasmussen \& Corbett, 2008).

In fact, trust between managers and employees are emphasized as the main barrier to implement telework and achieve desired performance. Constraint in the workplace environment can be the biggest barrier to telework adoption and implementation. This will be measured in this study using the hypothesis that:

H4: Workplace constraint is the main constraint of the telework adoption and implementation.

\subsection{Technology constraint}

Definition: For the purposes of this study, technology constraint relates to the lack of infrastructure for telework, and the lack of technical support for teleworkers.

Siha and Monroe (2006) found relatively few articles dealing with technological constraint. While technology is the backbone of a telework program, it is also a part of the organization's Information System. Therefore, the author gives an explanation that because of competitive issues, organizations prefer not to share their technological specifics openly. Despite the lack of literature, this research found the importance of technology choices, the availability of technology, and the quality of technology to the success of a telework program.

When in telework mode, the demand for information transfer is much greater because it often involves graphic and video communication (D'Arruda, 2001). Barron (2007) suggested that teleworkers should have more than one computer, a high speed wireless broadband, a cellular telephone, equipment functions such as fax, copy machine, scanner and printer. While having adequate technology infrastructure does not guarantee the success of telework program, the 
lack of infrastructure may be the main barrier. Ruppe and Howard (1998) suggested that telework should be adopted when relevant communication and security technologies such as intranet and/or Internet access is in place.

In general, organizations are concerned with the data and network accessibility and technology support which is needed to maintain productivity of employees (Mello, 2007). By summarizing two studies from GSA relating to telework barriers, Joice (2007) found that no single IT barrier is substantial enough to impede the growth of telework implementation. However, many agencies lack a proper approach to telework implementation, and strategies for IT support. Joice (2007) found that teleworkers often use existing IT infrastructure, equipment and personally owned resources from their home sites. Indeed, telecommuting has little impact on company IT resource and is often not considered in business and IT strategy.

Beside the technological infrastructure, the lack of infrastructure support such as secretaries, maintenance personnel and technical support can hinder the success of a telework project (Crandall \& Gao, 2005). In addition to technical support, various services such as postal distribution, library services, and social services may be delayed or impaired if teleworkers need them to fulfill their duties (Harpaz, 2002).

Meadows (2007) provided successful lessons from the US Patent and Trademark Office's telework program. The research showed that a robust IT system with strong IT support, sufficient bandwidth and appropriate collaboration tools such as email, voice mail, file sharing, screen sharing, instant messaging, video conference, data encryption and other capabilities is mandatory for a successful telework program. Such a system can be expensive, but its benefit is greater.

Baker et al. (2006) analyzed the impact of IT support, appropriateness of technology and other technology-related factors on the satisfaction and intention to use telework of employees. The positive result demonstrates the crucial role of technology to the growth of telecommuting. This research however does not mention the impact of technology in the intention of employers to use telework of employers.

In the above section on economic constraint, the findings indicate that technology cost is not a big problem. The technological constraint might also be easily solved by using existing infrastructure and equipment. However, the problem of technical support might be hard to solve, especially when there are many teleworkers and the distance from their home to the office is great. 


\subsection{Risk}

Definition: For the purpose of this study, risk is defined as the fear of the loss of sensitive information; health and other rights for teleworkers that can't be met.

Crandall and Gao (2005) were concerned with sensitive work information that can be compromised in a telecommuter environment. Since security at home can't compare to security in the office, the authors raise the question of what kind and how much work should be transferred in the home environment. Mello (2007) gave a negative example: in 2006, social security numbers and other personal information from 26.5 million US military personnel were contained on a laptop stolen from home.

A study in 2003 about technology barrier found that many organizations are unable to protect sensitive data because their security policies are not good, or teleworkers do not comply with them (Joice, 2007). However, the author admitted that IT security can be breached whether or not telework is involved. Joice (2007) suggested that implementing proper security training and guidance can mitigate the security risk of telework.

Employers have to be responsible for their teleworkers, and this responsibility involves extra cost. The US Occupational Safety and Hazard Administration has published policy guidelines on employee "home office" in 2000, which required employers to document any work-related injuries or illness regardless of where it happens, offices or home-based sites (Mello, 2007). D'Arruda (2001) found some liability that employers may need to cover, such as equipment damaged at employees' home or business guests injured at an employees' home.

Most industrial legislation does not cover the problems raised by telework, which allows employers to exploit teleworkers' rights. According to Tremblay (2002), until now no legislation ensures that working conditions of teleworkers are the same as those of other employees. However, D'Arruda (2001) suggested that some countries require employers to provide overtime payment, compensation and insurance for teleworkers, while these issues are not defined in other legislation. For example, in 2008, the US Secretary of Veterans Affairs had to apologize for the policy that required teleworkers to work 140 hours more than nontelework employees to be deemed qualified to work from home (Ruth \& Chaudhry, 2008).

Barron (2007) warned that for full time home-based workers, using their own contact details such as PO Box numbers and home phone numbers can be dangerous. They should use business information, and their personal information should not be shared. Ensuring all 
teleworkers' rights means more administrative work, more cost which can't be ignored, or employers may have to face lawsuits and fines.

\subsection{Workforce constraint}

Definition: For the ourposes of this study, workforce issues comprise of (1) positions suitable for telework; (2) employees suitable for telework; and (3) attitudes of employees about telework.

Bentley and Yoong (2000) defined three types of teleworkers: (1) employees who work at home for part of their working time; (2) totally home-based workers; and (3) self-employed home-based workers. Schweitzer and Duxbury (2006) agree with that classification though they suggested that some self-employed home-based workers may not be considered teleworkers.

Ruth and Chaudhry (2008) found that 40 percent of workers in US have jobs that could be performed at home. Meadows (2007) suggested that telework is appropriate for jobs relating to thinking and writing, for those who prepare reports, conduct data analysis, review cases and reports, or perform telephone intensive duties. Bentley and Yoong (2000) suggested that for knowledge workers who need to meet their colleagues or clients frequently, the nature of their job hinders the flexibility of teleworking. However, telework can be used as an alternative way to distribute their workload reasonably.

Table 2. Tasks carried out by teleworkers (Tremblay, 2002, p. 161).

\begin{tabular}{lcc}
\hline Type of task & Self-employed (\%) & Salaried (\%) \\
\hline Writing and word processing & 23.5 & 35.1 \\
Accounting & 17.5 & 18.55 \\
Management/administration & 10.2 & 16.6 \\
Software and website design & 14.0 & 11.4 \\
Sending, receiving and processing e-mail & 6.7 & 15.2 \\
CAD, computer graphics & 15.1 & 2.8 \\
Translation & 8.8 & 0.9 \\
\hline
\end{tabular}

Telework is not an opportunity for every industry. Fynes-Clinton (2005) quotes an opinion of a manager that the nature of retail is not suitable for implementing telecommuting. As such, most tasks in the retail industry involve interacting with customers, which can't be done from home. Tremblay (2002) explored the type of tasks that can be done by telework in Quebec, Canada. The result indicates that many tasks can be done partly or fully at home, most of them being done by computer. The author also found that men often hold autonomous professional jobs, while women often hold salaried clerical jobs. 
Though technology can facilitate collaboration, Tremblay (2002) suggested that telework is more appropriate for individual contribution based job. To be able to offer telework, jobs that required teamwork should include tasks that can be done outside the office.

In addition, when implementing a telework program, organizations need to face the challenge of how to find the right people for the right job (Siha \& Monroe, 2006). Many authors suggested that successful telecommuters need outstanding communication skills, work well independently, and be technically skilled (Watad \& Will, 2003). According to Meadows (2007), teleworkers should be able to work independently, be self-motivated, results oriented and thoroughly understand tasks and procedures. It is not appropriate for new employees who need "on-the-job" training.

Schweitzer and Duxbury (2006) explored characteristics of teleworkers and employers who offered telework opportunities in Canada. The results indicate that there are two types of teleworkers: (a) highly educated, experienced, full time, professional knowledge workers who perform their work at home during regular hours; and (b) part-time employees with experience who do computer-supported clerical, administrative and professional activities at home outside of business hours. This finding implies that teleworkers tend to be professionals who have experience.

Even if workers are eligible for telecommuting, they may not be willing to operate in that mode. Ruth and Chaudhry (2008) found reasons for this refusal, including difficulty to handle distraction, inability to work independently, problems in relationships with managers and coworkers, reluctance to miss out on collaborative opportunities, and unwillingness to send children to childcare. Crandall and Gao (2005) suggested that employees may not desire to telecommute for fear of an adverse impact on their career. Teleworkers are afraid of losing out on a good project and passing up chances for promotions.

The extensive literature review undertaken by Siha and Monroe (2006) found that while the workforce is the most popular issue of telework, most articles deal with benefit of telework, job satisfaction and motivation. Very few papers mentioned worker attitudes. The study of worker attitudes showed that teleworkers miss socialization, though they appreciate the chance of freedom and efficiency. Mello (2007) suggested that losing connection with managers and colleagues makes employees feel insecure about their "place" in the organization. Other employees also doubt absentees as serious employees. 
Research conducted on 600 managers in Australia and New Zealand showed that 71 percent of participants believe they face criticism from co-workers, while 61 percent believe they are the subject of negative gossip (Fynes-Clinton, 2005). This research also leads to an implication that no one thinks employees will work solely from home.

Bentley and Yoong (2000) study the attitude of knowledge workers about telework in two New Zealand organizations and found that participants prefer to work at the office most of their time in business hours, and consider telework as an adjunct working arrangement. That means they work at home after business hours, and their working day is longer. This study focused only on knowledge workers, and their sample was small so cannot reflect the attitude of all teleworkers.

Employees may not like to work at home, where they can't separate work and home life, and some may not know when to stop their work (D'Arruda, 2001). Without clear boundaries, teleworkers may spend too much time on work or home life, which results in a reduction of efficiency, or the stress of work-a-holic behavior (Harpaz, 2002).

Indeed, not all people, not all positions, and not all organizations can telework. This factor affects the decision making task of organizations around how to design an effective telework program.

\section{Research model}

Searching for the answer to our research question: "What are the most important factors that hinder the adoption and implementation of telework", a research model was developed to find the relationship between facilitators, constraints and telework implementation. The basic assumption of this study is that some constraints have negative influences on telework program, which affect organizational activities and performance. By verifying the four stated hypotheses, we can find out what positively or negatively influence the adoption and use of telework. 


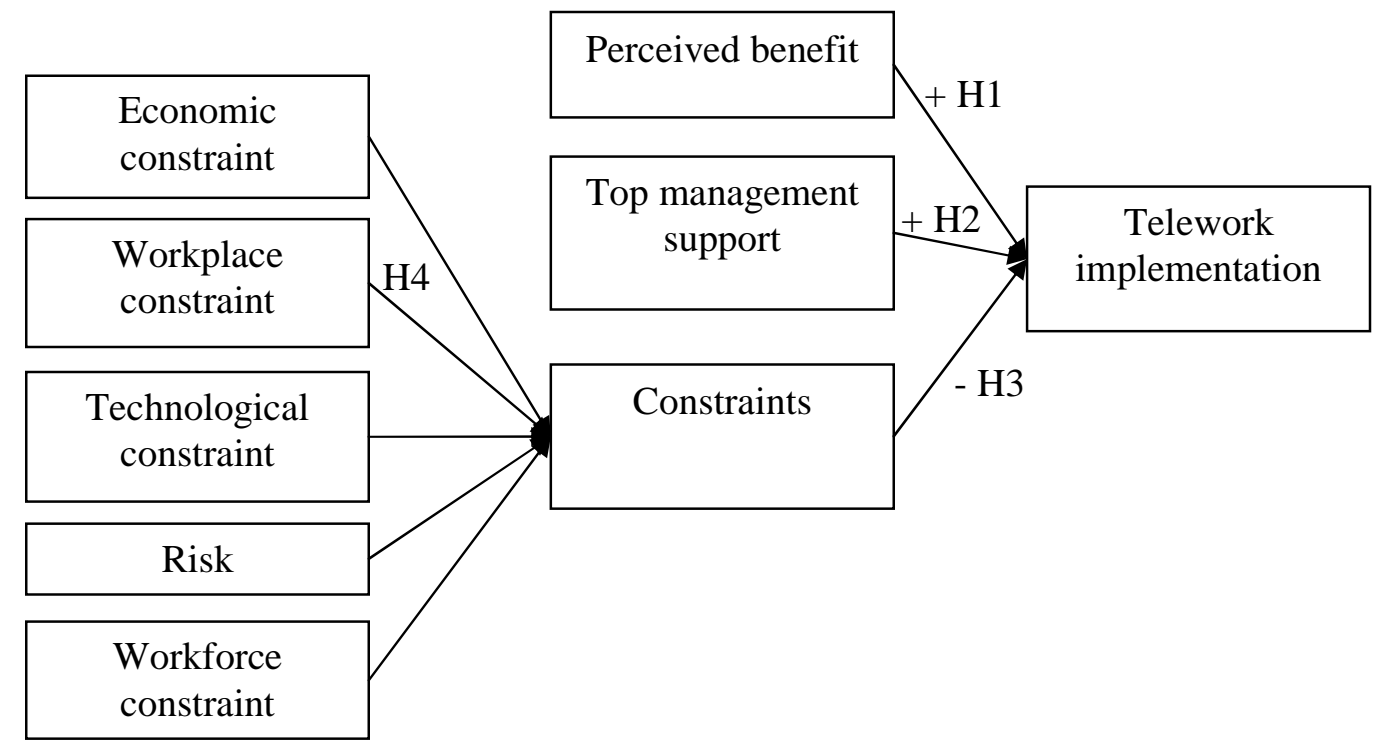

Figure 1. Research model of constraints to telework implementation

\section{Methodology}

The purpose of this research is to test four hypotheses in the above model. The quantitative method is useful in this case to evaluate the relationship between the dependent variable (Telework implementation) and three independent variables (Perceived benefit, Top management support and Constraints). A questionnaire was designed to collect what perceptions managers had about potential constraints on implementing teleowrk programs, as well as the size of their organizations. Size was used to differentiate organizations because it was expected to influence indirectly the proportion of the workforce involved in teleworking.

\section{Data collection}

Due to time limitations, participants were identified and invited from organizations with a high possibility of using telework. According to Schweitzer and Duxbury (2006), firms in Canada that offer telework opportunities tend to be larger companies in the education, health care and business service industries. Firms that offer other-site work are often in the construction industry, which are usually larger businesses. The study of telework in Quebec showed that 65 percent of teleworkers work in the service sector, while only 7 percent work in the manufacturing sector (Tremblay, 2002). This study only explored teleworkers that had signed an agreement, so it has left out informal teleworkers, who form a significant part of teleworking. 
According to Siha and Monroe (2006), a limited number of organizations have openly shared their experiences about their telecommuting's initiatives. In order to reach the largest range of potential candidates while maintaining their anonymity, an anonymous online survey was used. The online survey method was used also because of its ability to provide a fast response rate thus mitigating time constraints (Ilieva, Baron, \& Healey, 2002).

Invitations were sent by e-mail to 17 professional associations working in the ICT and commerce fields asking for their help by forwarding invitations to their corporate and individual members. Among them, four organizations agreed to help: the New Zealand Computer Society (NZCS), Telecom User Association New Zealand (TUANZ), the Sustainable Business Network and the Institution of Professional Engineers New Zealand (IPENZ). The survey was open from 10 March to 30 April 2010 and received 23 responses. Two of these responses did not answer any questions, so there were in total 21 valid responses.

\section{Measurement}

In the literature review section, we have identified all possible constraints of a telework program. The research model (Figure 1) has shown the relationship between all variables in this study. The proportion of the workforce involved in teleworking is used to measure the performance of a telework program in an organization. This study evaluate the influences of perceived benefit, top management support and five factors of constraints on telework implementation. While perceived benefit and top management support are expected to positively influence telework implementation, the lack of them can hinder the telework program. Therefore, according to Theory of Constraint, these two factors can also be considered constraints to telework implementation.

The dependent variable in this study is the proportion of organizations' workforces involved in teleworking. This variable has five categories consistent with the study of Rasmussen and Corbett (2008), which are: 0\%; 1-5\%; 6-10\%; 11-20\%; 21-50\%; and 50\%+.

There are seven independent variables. These variables and the number of questions relating to each are:

- Perceived benefit (4 questions);

- Top management support (2 questions);

- Economic constraint (2 questions);

- Workplace constraint (5 questions); 
- Technology constraint (3 questions);

- Risk (3 questions); and

- Workforce constraint (3 questions).

The definitions of each variable in section 3 (Literature review) have highlighted some important aspects of each constraint. Each aspect was addressed by one question in the questionnaire. Questions in the perceived benefit and top management support categories expressed the positive impacts of these on telework implementation. Most of the questions in the constraints category explore the negative effects of constraints on telework implementation. However, some questions were worded in a positive way in order to avoid response bias. Outcomes of these questions were coded in reverse before being analysed. Details of which questions were coded in reverse is showed in Table 4.

Participants were asked to specify to what extent these questions are applicable to telework in their organization using one of five levels: Not at all, Unlikely, Undecided, Likely and Definitely. The control variable organization size is used to measure the relationship between size and these constraints. This study used the classification of organization size from Statistics New Zealand (2008), which defines small organizations as those having 19 or fewer employees; while large organizations have 50 or more employees. Finally, participants have a chance to directly indicate what, if any, are the obstacles for telework programs in their organization, and contribute additional thoughts.

\section{Validation method}

Due to the exploratory nature of this study, multiple linear regression analysis was selected. The data was analyzed using SPSS. Hypotheses were tested by analyzing the relationship between the dependant variable (proportion of workforce involved in teleworking) and independent variables in each specific category.

In the field of IS research, Straub (1989) suggested that the researcher should assess as many validities as possible, using final administered instruments and/or pre-test, pilot test validities instrument. Boudreau, Gefen, and Straub (2001) found that this guideline is still valid in recent IS research. Due to time limitations, this study assessed the following validities:

Reliability: Cronbach's coefficient $\alpha$ values of each item were evaluated to check for internal consistency.

Construct validity: Factor analysis was undertaken to examine the construct of the constraints category. To be consistent with the research model, the number of factors were fixed to 5 . 


\section{Data analysis}

\section{Validities testing}

The Cronbach's $\alpha$ values of all items are from 0.749 to 0.852 , which indicated adequate internal consistency (Table 3).

Table 3. Reliability of the research model

\begin{tabular}{|l|c|}
\hline \multicolumn{1}{|c|}{ Construct } & Cronbach's $\boldsymbol{\alpha}$ \\
\hline 1. Perceived benefit & 0.827 \\
\hline 2. Top management support & 0.862 \\
\hline 3. Economic constraint & 0.749 \\
\hline 4. Workplace constraint & 0.776 \\
\hline 5. Technological constraint & 0.787 \\
\hline 6. Risk & 0.775 \\
\hline 7. Workforce constraint & 0.852 \\
\hline
\end{tabular}

Factor analysis was used to check the construct validity of the constraints category. In Table 4, we can see that item 3 (Economic constraint) and item 7 (Workforce constraint) each measures different factors with high validities. However, with exceptions in some questions, item 4 (Workplace constraint), item 5 (Technological constraint) and item 6 (Risk) seem to measure the same thing. We consider that these items reflected different aspects of constraints in an organizational context. The economic constraint, organizational constraint, and workforce constraint were manifested in the research model. Therefore, we can still consider the construct of the research model to be reasonably valid. However, future research should be careful with this type of organizational constraint when designing a research model.

Table 4. Factor analysis of the research model

\begin{tabular}{|c|c|c|c|c|c|c|}
\hline \multirow{2}{*}{ Constraint } & \multirow{2}{*}{ Item description } & \multicolumn{5}{|c|}{ Factor } \\
\hline & & 1 & 2 & 3 & 4 & 5 \\
\hline \multirow[t]{2}{*}{$\begin{array}{l}\text { 3. Economic } \\
\text { constraint }\end{array}$} & $\begin{array}{l}\text { 3. } 1 \text { Hardware, software and infrastructure } \\
\text { expenses for telework are significant }\end{array}$ & .425 & .175 & .797 & .177 & .049 \\
\hline & $\begin{array}{l}\text { 3.2 Changing the administrative system for } \\
\text { telework is costly }\end{array}$ & .006 & .101 & .691 & -.167 & -.125 \\
\hline \multirow[t]{4}{*}{$\begin{array}{l}\text { 4. Workplace } \\
\text { constraint }\end{array}$} & $\begin{array}{l}\text { 4.1 Losing one person in a small office because } \\
\text { of teleworking would be a problem for us }\end{array}$ & .115 & .186 & -.073 & -.070 & .851 \\
\hline & $\begin{array}{l}\text { 4.2 The telework program requires the } \\
\text { organizational culture to change }\end{array}$ & .069 & .796 & .330 & .274 & .176 \\
\hline & 4.3 Telework hinders teamwork & .379 & .037 & -.069 & .455 & .593 \\
\hline & 4.4 Managers lack trust in teleworkers & .615 & .675 & -.051 & .093 & .001 \\
\hline
\end{tabular}




\begin{tabular}{|c|c|c|c|c|c|c|}
\hline & 4.5 Managing absent workers is difficult & .276 & .857 & .131 & -.074 & .139 \\
\hline \multirow[t]{3}{*}{$\begin{array}{l}\text { 5.Technological } \\
\text { constraint }\end{array}$} & $\begin{array}{l}\text { 5.1 Our current telecommunication technology } \\
\text { supports working at home }(*)\end{array}$ & .376 & .262 & -.072 & .863 & .037 \\
\hline & $\begin{array}{l}5.2 \text { Our company has appropriate infrastructure } \\
(*)\end{array}$ & .527 & .441 & .063 & .375 & .086 \\
\hline & 5.3 Telework requires too much IT support & .177 & .533 & .108 & .350 & .402 \\
\hline \multirow[t]{3}{*}{ 6. Risk } & $\begin{array}{l}\text { 6.1 Sensitive information can be lost through } \\
\text { teleworking }\end{array}$ & -.289 & .570 & .479 & .394 & .148 \\
\hline & $\begin{array}{l}\text { 6.2 Telework creates problems with working } \\
\text { hours and overtime pay rate }\end{array}$ & .203 & .592 & .508 & .416 & -.164 \\
\hline & $\begin{array}{l}6.3 \text { It is hard to ensure the safety and health of } \\
\text { teleworkers }\end{array}$ & .019 & .100 & .721 & .021 & .019 \\
\hline \multirow[t]{3}{*}{$\begin{array}{l}\text { 7. Workforce } \\
\text { constraint }\end{array}$} & $\begin{array}{l}\text { 7.1 Our organization has tasks that are suitable } \\
\text { for teleworking }(*)\end{array}$ & .793 & .114 & .261 & .106 & .008 \\
\hline & $\begin{array}{l}\text { 7.2 Existing employees are suitable for } \\
\text { teleworking }(*)\end{array}$ & .866 & .204 & -.012 & .100 & .143 \\
\hline & 7.3 Employees like to do telework $(*)$ & .722 & .041 & .075 & .193 & .310 \\
\hline
\end{tabular}

Extraction Method: Principal Axis Factoring.

Rotation Method: Varimax with Kaiser Normalization.

(*) Item was coded reversely before being analyzed

Table 5 showed the telework implementation status in participating organizations. Only $10 \%$ of responses in our sample did not implement any type of telework. However, according to Rasmussen and Corbett (2008), 80\% organizations in New Zealand do not use telework. One possible explanation is that if people do not have an interest in telework, they will ignore research relating to it. Indeed, an anonymous online survey can only consult people interested in telework. According to Ilieva et al. (2002), web-based data collection methods often results in a sample of respondents that is not representative of the desired population. Therefore, other instruments are needed to reach a full range of New Zealand organizations.

Table 5. Result of proportion of workforces involved in teleworking

\begin{tabular}{|c|l|l|l|l|}
\hline$\#$ & Answer & Response & $\%$ \\
\hline 1 & $0 \%$ & & 2 & $10 \%$ \\
\hline 2 & $1-5 \%$ & & 7 & $33 \%$ \\
\hline 3 & $6-10 \%$ & & 1 & $5 \%$ \\
\hline 4 & $11-20 \%$ & & 4 & $19 \%$ \\
\hline 5 & $21-50 \%$ & & 4 & $19 \%$ \\
\hline 6 & $50 \%+$ & & 3 & $14 \%$ \\
\hline & Total & & 21 & $100 \%$ \\
\hline
\end{tabular}




\section{Hypotheses testing}

Table 6 summarized the relationship between all independent variables and the dependent variables (proportion of workforces involved in teleworking). The overall result showed that the dependent variable can be explained $100 \%$ by all independent variables. This result is not surprising because there is no significant difference between the sample size (21) and the number of independent variables (23). Therefore, assumption cannot be made about this result.

Table 6. Summary of the research model

\begin{tabular}{|l|r|r|r|r|}
\hline Model & R & R Square & $\begin{array}{c}\text { Adjusted R } \\
\text { Square }\end{array}$ & $\begin{array}{c}\text { Std. Error of } \\
\text { the Estimate }\end{array}$ \\
\hline 1 & $1.000^{\mathrm{a}}$ & 1.000 & & \\
\hline
\end{tabular}

a. Predictors: All independent variables

Table 7 summarized the regression analyses of each constraint category on the proportion of telework implementation. There are clear differences between $\mathrm{R}^{2}$ and adjusted $\mathrm{R}^{2}$ in all results, which showed that the finding was strongly susceptible to the sample size. However, the study found significant relationships between three main independent variables (perceived benefit, top management support and constraints) and the proportion of telework implementation. Therefore, we can conclude that $\mathrm{H} 1, \mathrm{H} 2$ and $\mathrm{H} 3$ were supported in this study: Perceived benefit and top management support positively influences telework implementation, while constraints category has a negative impact..

Table 7. Impacts of each constraint on the proportion of telework implementation

\begin{tabular}{|l|r|r|r|r|}
\hline \multicolumn{1}{|c|}{ Model } & R & R Square & \multicolumn{1}{c|}{$\begin{array}{c}\text { Adjusted R } \\
\text { Square }\end{array}$} & $\begin{array}{c}\text { Std. Error of } \\
\text { the Estimate }\end{array}$ \\
\hline 1. Perceived benefit & .695 & .484 & .355 & 1.279 \\
\hline 2. Top management support & .780 & .609 & .568 & 1.088 \\
\hline 3. Economic constraint & .059 & .004 & -.101 & 1.736 \\
\hline 4. Workplace constraint & .693 & .481 & .318 & 1.366 \\
\hline 5. Technological constraint & .663 & .439 & .346 & 1.338 \\
\hline 6. Risk & .120 & .014 & -.150 & 1.774 \\
\hline 7. Workforce constraint & .444 & .197 & .063 & 1.601 \\
\hline
\end{tabular}

While in the constraints category, workplace constraint has the strongest relationship with the proportion of telwork implementation (0.481), its score is not significantly higher than technological constraint (0.439). Moreover, this relationship is not as strong as those relating to top management support (0.609) and perceived benefit (0.484). Therefore, we cannot 
conclude that workplace constraint is the main constraint of telework adoption and implementation. H4 was not supported in this study.

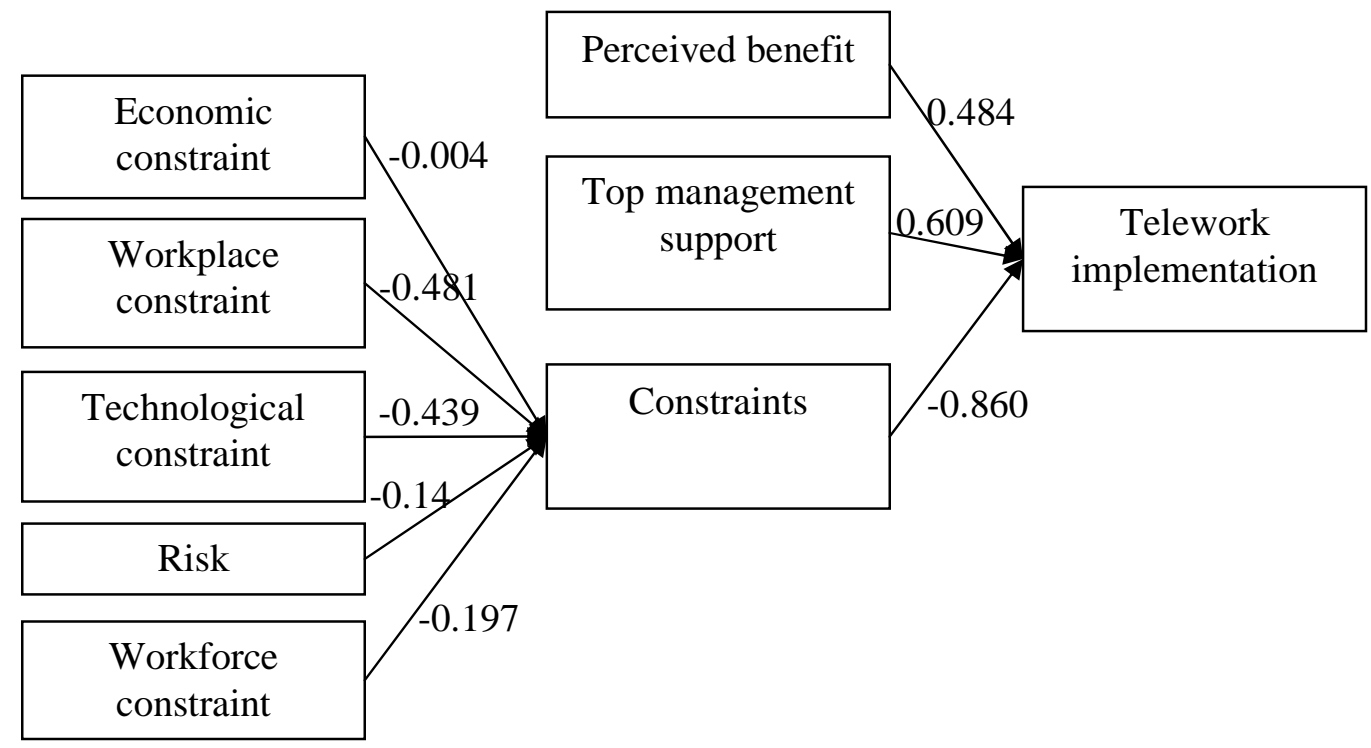

Figure 2. Result of constraints to telework implementation

Table 8 showed the main constraints of telework implementation that were directly identified by participants. Lack of top management support and workforce constraints were found to be the two biggest constraints of telework implementation. While the importance of top management support was demonstrated, workforce constraint was not a significant predictor of telework implementation in the above analysis. This finding implies that the workforce constraint could be a universal constraint, or it has not been fully explored in this research. Therefore, we need to take a closer look into the workforce constraint.

Table 8. Main constraints of telework specified by participants

\begin{tabular}{|c|c|c|c|c|}
\hline$\overline{\#}$ & Answer & & $\overline{\text { Response }}$ & $\%$ \\
\hline 1 & No real benefit & & 4 & $22 \%$ \\
\hline 2 & Lack of top management support & & 9 & $50 \%$ \\
\hline 3 & Economic constraints & & 0 & $0 \%$ \\
\hline 4 & Workplace constraints & 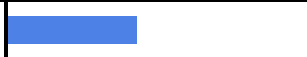 & 4 & $22 \%$ \\
\hline 5 & Technology constraints & & 3 & $17 \%$ \\
\hline 6 & Risks & & 3 & $17 \%$ \\
\hline 7 & Workforce constraints & & 9 & $50 \%$ \\
\hline 8 & Other (please specify): & & 0 & $0 \%$ \\
\hline
\end{tabular}




\section{Extracting meaningful statistics}

In the following section, we examined the impact of organization size on telework implementation, including the fear of losing people in a small office.

Table 9. The impact of organization size to telework implementation

\begin{tabular}{|l|r|r|r|r|}
\hline Model & \multicolumn{1}{|c|}{ R } & \multicolumn{1}{c|}{ R Square } & \multicolumn{1}{c|}{$\begin{array}{c}\text { Adjusted R } \\
\text { Square }\end{array}$} & $\begin{array}{l}\text { Std. Error of } \\
\text { the Estimate }\end{array}$ \\
\hline 1 & $.621^{\mathrm{a}}$ & .386 & .355 & 1.328 \\
\hline 2 & $.623^{\mathrm{b}}$ & .388 & .323 & 1.361 \\
\hline
\end{tabular}

a. Predictors: (Constant), 4. Losing one person in a small office because of teleworking would be a problem for us

b. Predictors: (Constant), 4. Losing one person in a small office because of teleworking would be a problem for us, 1 . Size of organization

Table 9 examined the impact of organizational size on telework implementation. The relationship between the fear of losing people in a small office and the dependent variable is significant and can explain $38.6 \%$ of it. However, the study did not find a direct link between the size of organization and the proportion of workforce involved in teleworking. The relation between the size of organization and the fear of losing people in a small office was not significant (Table 10).

Table 10. Relationship between the fear of losing people and the size of organization

\begin{tabular}{|ll|r|r|}
\hline & $\begin{array}{c}\text { 4. Losing one person in } \\
\text { a small office... }\end{array}$ & $\begin{array}{c}\text { 1. Size of } \\
\text { organization }\end{array}$ \\
\hline 4. Losing one person in a \\
small office ... & Pearson Correlation & 1 & -.141 \\
& Sig. (2-tailed) & 22 & .533 \\
& $\mathrm{~N}$ & -.141 & 22 \\
\hline 1. Size of organization & Pearson Correlation & .533 & 1 \\
& Sig. (2-tailed) & 22 & 22 \\
& $\mathrm{~N}$ & & \\
\end{tabular}

We then looked closer into responses for each question. Positive responses (Likely; Definitely) were compared with negative responses (Not at all; Unlikely) to find the tendency in participants' perception about telework constraints. In Table 11, we can see that telework tends to increase productivity (12 positive/4 negative responses). The result of 10 positive responses and 3 negative responses clearly indicates the benefit of telework in delivering competitive advantage. However, the economic benefit of telework (reducing real estate expense) was doubtful (7 positive/11 negative responses). 
Table 11. Report of perceived benefits

\begin{tabular}{|c|c|c|c|c|c|c|c|c|}
\hline \# & Question & Not at all & Unlikely & Undecided & Likely & Definitely & Responses & Mean \\
\hline 1 & $\begin{array}{l}\text { Telework increases } \\
\text { productivity }\end{array}$ & 0 & 4 & 5 & 7 & 5 & 21 & 3.62 \\
\hline 2 & $\begin{array}{l}\text { Telework provides more } \\
\text { recruitment options }\end{array}$ & 2 & 6 & 1 & 9 & 2 & 20 & 3.15 \\
\hline 3 & $\begin{array}{l}\text { Telework reduce real estate } \\
\text { expense }\end{array}$ & 4 & 7 & 3 & 4 & 3 & 21 & 2.76 \\
\hline 4 & $\begin{array}{l}\text { Benefits of telework give } \\
\text { competitive advantages }\end{array}$ & 2 & 1 & 8 & 7 & 3 & 21 & 3.38 \\
\hline
\end{tabular}

Table 12. Report of top management support

\begin{tabular}{|c|c|c|c|c|c|c|c|c|}
\hline \# & Question & Not at all & Unlikely & Undecided & Likely & Definitely & Responses & Mean \\
\hline 1 & $\begin{array}{l}\text { Top management is committed } \\
\text { to telework implementation }\end{array}$ & 0 & 7 & 1 & 7 & 6 & 21 & 3.57 \\
\hline 2 & $\begin{array}{l}\text { Our organization has a } \\
\text { champion for telework program }\end{array}$ & 9 & 2 & 4 & 2 & 4 & 21 & 2.52 \\
\hline
\end{tabular}

In section 2, the analysis has emphasized the role of top management support in telework projects. In Table 12, we found that top management were quite committed to telework implementation (13 positive/7 negative responses). However, there is the lack of champion with 6 positive/11 negative responses. Lack of champion could be what participants are worried about in telework projects.

Table 13. Report of Economic constraint

\begin{tabular}{|c|c|c|c|c|c|c|c|c|}
\hline \# & Question & Not at all & Unlikely & Undecided & Likely & Definitely & Responses & Mean \\
\hline 1 & $\begin{array}{l}\text { Hardware, software and } \\
\text { infrastructure expenses for } \\
\text { telework are significant }\end{array}$ & 2 & 6 & 2 & 8 & 3 & 21 & 3.19 \\
\hline 2 & $\begin{array}{l}\text { Changing the administrative } \\
\text { system for telework is costly }\end{array}$ & 3 & 6 & 3 & 6 & 3 & 21 & 3.00 \\
\hline
\end{tabular}

Table 13 showed that positive and negative responses of infrastructure and administrative system cost are quite balanced (11 positive/8 negative and 9 positive/9 negative responses respectively). Economic constraint therefore is not clearly identified by participants. Not only economic constraint, economic benefit was also not recognized by participants (Table 11). Moreover, economic constraint is not a good predictor of the proportion of telework implementation; with the result of the regression analysis was 0.04 (Table 7). Economic constraint also received 0 response in table 8 which summarized the main constraints of telework implementation directly specified by participants. Therefore, we can conclude that economic issues were not significant in telework. 
Table 14. Report of Workplace constraint

\begin{tabular}{|c|c|c|c|c|c|c|c|c|}
\hline$\#$ & Question & Not at all & Unlikely & Undecided & Likely & Definitely & Responses & Mean \\
\hline 1 & $\begin{array}{l}\text { Losing one person in a small } \\
\text { office because of teleworking } \\
\text { would be a problem for us }\end{array}$ & 4 & 7 & 5 & 1 & 4 & 21 & 2.71 \\
\hline 2 & $\begin{array}{l}\text { The telework program requires } \\
\text { the organizational culture to } \\
\text { change }\end{array}$ & 2 & 2 & 4 & 8 & 5 & 21 & 3.57 \\
\hline 3 & Telework hinders teamwork & 3 & 10 & 5 & 3 & 0 & 21 & 2.38 \\
\hline 4 & $\begin{array}{l}\text { Managers lack trust in } \\
\text { teleworkers }\end{array}$ & 3 & 7 & 2 & 9 & 0 & 21 & 2.81 \\
\hline 5 & $\begin{array}{l}\text { Managing absent workers is } \\
\text { difficult }\end{array}$ & 2 & 3 & 5 & 6 & 5 & 21 & 3.43 \\
\hline
\end{tabular}

The report of Workplace Constraint showed that the fear of losing workers in a small office seems unclear (5 positive/11 negative responses). Participants agreed that telework does not hinder teamwork (3 positive/10 negative responses); while being ambiguous about the trust of managers in employees ( 9 positive/10 negative responses).

Table 15. Report of Technological constraint

\begin{tabular}{|c|c|c|c|c|c|c|c|c|}
\hline \# & Question & Not at all & Unlikely & Undecided & Likely & Definitely & Responses & Mean \\
\hline 1 & $\begin{array}{l}\text { Our current telecommunication } \\
\text { technology supports working at } \\
\text { home }\end{array}$ & 1 & 1 & 1 & 8 & 10 & 21 & 4.19 \\
\hline 2 & $\begin{array}{l}\text { Our company has appropriate } \\
\text { infrastructure }\end{array}$ & 1 & 1 & 4 & 6 & 9 & 21 & 4.00 \\
\hline 3 & $\begin{array}{l}\text { Telework requires too much IT } \\
\text { support }\end{array}$ & 1 & 8 & 6 & 3 & 3 & 21 & 2.95 \\
\hline
\end{tabular}

Participants' responded positively about technology. They feel that telecommunication technology is good for telework (18 positive/2 negative responses), their organization has appropriate infrastructure (15 positive/2 negative responses) and IT support is not a problem (6 positive/9 negative responses). Participants were more worried about IT support than technical constraints, which is consistent with the study of Baker et al. (2006).

Table 16. Report of Risks

\begin{tabular}{|c|c|c|c|c|c|c|c|c|}
\hline \# & Question & Not at all & Unlikely & Undecided & Likely & Definitely & Responses & Mean \\
\hline 1 & $\begin{array}{l}\text { Sensitive information can be } \\
\text { lost through teleworking }\end{array}$ & 1 & 8 & 2 & 6 & 4 & 21 & 3.19 \\
\hline 2 & $\begin{array}{l}\text { Telework creates problems } \\
\text { with working hours and } \\
\text { overtime pay rate }\end{array}$ & 2 & 8 & 3 & 7 & 1 & 21 & 2.86 \\
\hline 3 & $\begin{array}{l}\text { It is hard to ensure the safety } \\
\text { and health of teleworkers }\end{array}$ & 1 & 7 & 6 & 5 & 2 & 21 & 3.00 \\
\hline
\end{tabular}


Positive and negative responses to risk were found with nearly the same amount. Information security risk (10 positive/9 negative responses), working hours and payrate risks (8 positive/10 negative responses) and safety of teleworkers (7 positive/8 negative responses). Risks was also not a good predictor of the proportion of telework implementation with the regression analysis' result of 0.14 . This result provided no clear implication at this state.

Table 17. Report of Workforce constraint

\begin{tabular}{|c|l|c|c|c|c|c|c|c|}
\hline$\#$ & Question & Not at all & Unlikely & Undecided & Likely & Definitely & Responses & Mean \\
\hline 1 & $\begin{array}{l}\text { Our organization has tasks that } \\
\text { are suitable for teleworking }\end{array}$ & 0 & 4 & 2 & 5 & 10 & 21 & 4.00 \\
\hline 2 & $\begin{array}{l}\text { Existing employees are } \\
\text { suitable for teleworking }\end{array}$ & 0 & 2 & 2 & 8 & 9 & 21 & 4.14 \\
\hline 3 & Employees like to do telework & 0 & 0 & 9 & 6 & 6 & 21 & 3.86 \\
\hline
\end{tabular}

Participants are very positive about workforce issues: their organizations have tasks for teleworking (15 positive/4 negative responses); employees are suitable for teleworking (17 positive/2 negative responses) and they like to do telework (12 positive/0 negative responses). Therefore, we cannot confirm the supposition made in the section 2 that workforce constraint is a universal constraint. However, workforce constraint is still one of the two biggest constraints identified by participants (Table 5). Therefore, there may be other workforce constraints that have not been explored in this study.

\section{Discussion}

\section{Discussion of the finding}

This study examined the relationship of various independent factors on a proportion of the workforce involved in telework in New Zealand businesses. The research model has been validated by the reliability and construct validities test. The result indicated adequate internal consistency across each category. The construct of the research model is reasonably valid with workplace constraint, technological constraint and risk have a close meaning which measures different aspects of organizational constraint.

Because of the limitation in the sample size, findings from this research should only be considered initial understanding of constraint to telework implementation, and should be verified by future research. The result of this study showed that some factors have stronger impacts on telework implementations than the others. Some constraints that were reported in 
the literature was not supported in this study. In the following section, we will discuss four of the main findings of this research.

First, we found that perceived benefit and top management support have positive effects; while constraints have a negative impact on telework implementation. Hypothesis 1, 2 and 3 were supported in this study. In the constraints category, workplace constraint has the strongest relationship with telework implementation. However, top management support has a stronger influence on telework implementation than workplace constraint. Therefore, we cannot confirm Hypothesis 4 which predicted that workplace constraint is the main constraint of telework programs. In addition, lack of top management support and workforce constraint were directly specified by participants to be the two main constraints of telework implementation in an organization. This study suggested that managers and researchers should pay more attention to top management support as one of the most important constraints of telework projects. This study also reflected the lack of champion for telework project in an organization. Therefore, managers should find a champion to ensure success of the telework project. Future research should explore why top management support is the main constraint, and why there is a lack of champion in telework projects.

Second, this study confirmed that the fear of losing people in a small office existed in New Zealand businesses, and significantly affected the proportion of telework implementations. However, the study showed no link between the size of the organization and the fear of losing people, as well as the proportion of telework implementation. This finding reflects the attitude of managers in telework projects rather than the actual impact of the size of the organization. Therefore, to successfully implement telework, managers should prepare a communication plan to reduce this kind of fear.

Third, the results of this study supported literature findings about telework implementation. This study found significant evident that telework increases productivity, and delivers competitive advantage. Participants also showed their worries about the constraints of culture and managing absent workers.

Fourth, some constraints were not supported in this study. The economic benefit and constraint of telework were not found by participants. The importance of employee trust which had been emphasized in the literature was not supported in this study. Telework was also not found to hinder teamwork; and in general, workplace constraints do not show a strong impact on telework implementation. A possible explanation is that most participating 
organizations have adopted some forms of telework, so some constraints have been mitigated. Future research could verify this result with a larger sample size.

Technological constraints and risks were not supported in this study. A possible explanation is that New Zealand has a good ICT infrastructure and service which can support telework implementation. Another possible explanation is that participants are high-level managers, who do not care about details. Nevertheless, to ensure a successful telework project, organization should take into account all relevant factors, even if they are not significant.

Workforce constraint was not found to be significant in this study. Participants agreed that their organization has tasks for teleworking; employees can do and like to do telework. Because in this sample, most organization has already implemented telework, then their organization and employees must be prepared for telework. Despite these positive responses, workforce constraint was still specified as one of the biggest constraints of telework implementation. There was also an additional comment: "Most of the comments do not relate to our organization". Therefore, we assume that there are other workforce constraints that have not been explored in this study. Future research should pay more attention into the workforce constraint, and revise this research model.

\section{Limitations}

The main limitation of this study was the small number of responses due to time constraint, organization's hesitation in sharing telework experience (Siha \& Monroe, 2006), and the low response rate nature of online surveys (Ilieva et al., 2002). Since it's already hard to ask organizational opinions about telework, future research should be undertaken in an appropriate amount of time to achieve an acceptable sample size. Future research should also try to implement pre-test, pilot test instruments to ensure validity of the research model. This research model has been tested with a reliability and construct validity test. Therefore, future research can repeat this research, but should revise the construct of the workforce constraint.

The anonymous nature of the online survey makes it hard to check the validity of responses. Since participants participated voluntarily, this study cannot be claimed to be the study of telework in New Zealand businesses. Therefore, non-response bias was not checked in this study. Because participants joined this research voluntarily, we lack opinions from some important parts of industry that may not be interested in telework such as the retail industry, as suggested by Fynes-Clinton (2005). Therefore, other data collection methods are needed to reach a desired population - New Zealand businesses in general. 
While extensive review of the literature showed that most of New Zealand organizations do not use telework, opinions of non-adopters were lacking in this study. Moreover, Siha and Monroe (2006) suggested the differences between adopters and non-adopters of teleworking that have not been identified in academic research. The study conducted by Perez, Sanchez, Carnicer, and Jimenez (2004) showed that telework adopters have some different characteristics in comparison to non-adopters. For instance, they are more sensible to innovation opportunities, are located in areas with worse road congestion and traffic conditions, and have a management monitoring system more oriented to results than nonadopters. In general, future research should use other data collection methods that can identify participants' demographics and seek opinions from non-adopters.

\section{Conclusion}

While telework has many benefits, the reasons for its slow growth have not been identified. This study is an early research study which explored overall constraints of telework adoption and implementation in the context of New Zealand business. We have examined the impacts of perceived benefit of telework, top management support and five constraints factors on the proportion of telework implementation. This study has confirmed the positive impact of perceived benefit and top management support, and the negative impact of constraints on telework implementation. This study recognized the importance of top management in facilitating telework implementation in the context of New Zealand; the importance of workplace constraint was not supported.

This study has confirmed telework literature findings in some areas such as the benefits of telework, constraints of culture change, and the fear of losing people in a small office. Economic benefits and constraints of telework were not found by this study. Moreover, respondents did not emphasize trust as a main constraint on telework. Respondents were also very positive about workforce issues; possibly because most participating organizations have implemented telework to a certain degree. However, participants were still worried about workforce constraint, which implied that workforce constraint has not been fully explored in the research model.

In conclusion, this study has provided an initial understanding of constraints in telework adoption and implementation. We suggest that managers should pay more attention to top management support and culture change, while not neglecting other factors in a telework 
project. Future research should validate some of the findings from this study. The author suggests that researchers should use other data collection methods that can identify participants' demographics; seek the opinions of non-adopters; and revise the research model, especially in terms of workforce constraints.

\section{Bibliography}

Baker, E., Avery, G. C., \& Crawford, J. (2006). Home alone: The role of technology in telecommuting. Information Resources Management Journal, 19(4), 1-22.

Barron, J. (2007). Making the virtual leap: ten issues to consider about telecommuting. Industrial and commercial training, 39(7), 396-399.

Bentley, K., \& Yoong, P. (2000). Knowledge work and telework: an exploratory study. Internet Research, 10(4), 346.

Boudreau, M., Gefen, D., \& Straub, D. W. (2001). Validation in information systems research: A state-of-the-art assessment. MIS Quarterly, 25(1), 1-15.

Corso, M., Giacobbe, A., Martini, A., \& Pellegrini, L. (2006). What knowledge management for mobile workers? Knowledge and Process Management, 13(3), 206-217.

Crandall, W., \& Gao, L. (2005). An update on telecommuting: review and prospects for emerging issues. S.A.M. Advanced Management Journal, 70(3), 30-37.

D'Arruda, K. A. (2001). Telecommuting: Factors to consider. AAOHN Journal, 49(10), 471477.

Fynes-Clinton, J. (2005). Make home work. The Courier - Mail, 12.

Gendreau, R. (2007). The new techno culture in the workplace and at home. Journal of American Academy of Business, 11(2), 191-196.

Geri, N., \& Ahituv, N. (2008). A Theory of Constraints approach to interorganizational systems implementation. Information System E-Bussiness Management, 6, 341-360.

Gupta, M. C., \& Boyd, L. H. (2008). Theory of constraints: a theory for operations management. International Journal of Operations \& Production Management, 28(10), 991-1012.

Harpaz, I. (2002). Advantages and disadvantages of telecommuting for the individual, organization and society. Work Study, 51(2/3), 74-80. 
Ilieva, J., Baron, S., \& Healey, N. M. (2002). Online surveys in marketing research: Pros and cons. International Journal of Market Research, 44(3), 361-382.

Joice, W. (2007). Implementing telework: the technology issue. Public Manager, 36(2), 6468.

Kakihara, M., \& Sorensen, C. (2004). Practising mobile professional work: tales of locational, operational, and interactional mobility. The Journal of Policy, Regulation and Strategy for Telecommunications, 6(3), 180-187.

Lee, Y., Chu, P., \& Tseng, H. (2009). Exploring the relationships between information technology adoption and business process reengineering. Journal of Management and Organization, 15(2), 170-185.

Meadows, V. (2007). Versatile bureaucracy: A telework case study. Public Manager, 36(4), 33-37.

Mello, J. A. (2007). Managing telework programs effectively. Employee Responsibilities and Rights Journal, 19(4), 247-261.

Munkvold, B. E. (1999). Challenges of IT implementation for supporting collaboration in distributed organizations. European Journal of Information Systems, 8(4), 260-272.

Perez, M. P., Sanchez, A. M., Carnicer, P. D. L., \& Jimenez, M. J. V. (2004). A technology acceptance model of innovation adoption: the case of teleworking. European Journal of Innovation Management, 7(4), 280-291.

Rahman, S. (1998). Theory of constraints: A review of the philosophy and its applications. International Journal of Operations \& Production Management, 18(4), 336.

Rasmussen, E., \& Corbett, G. (2008). Why isn't teleworking working? New Zealand Journal of Employment Relations, 33(2), 20-32.

Reid, R. A., \& Shoemaker, T. E. (2006). Using the Theory of Constraints to focus organizational improvement efforts: Part 1 - Defining the problem. American Water Works Association. Journal, 98(7), 63-75.

Ruppe, C. P., \& Howard, G. S. (1998). Facilitating innovation adoption and diffusion: The case of telework. Information Resources Management Journal, 11(3), 5-14.

Ruth, S., \& Chaudhry, I. (2008). Telework: a productivity paradox? IEEE Internet Computing, 12(6), 87-90. 
Schweitzer, L., \& Duxbury, L. (2006). Benchmarking the Use of Telework Arrangements in Canada. Canadian Journal of Administrative Sciences, 23(2), 105-117.

Siha, S. M., \& Monroe, R. W. (2006). Telecommuting's past and future: a literature review and research agenda. Business Process Management, 12(4), 455-482.

Statistics New Zealand. (2008). Business Operations Survey: 2008 Tables - Statistics New Zealand. Statistics New Zealand. Retrieved January 18, 2010, from http://www.stats.govt.nz/methods_and_services/access-data/tables/business-opsurvey-2008.aspx

Straub, D. W. (1989). Validating Instruments In MIS Research/sup 1. MIS Quarterly, 13(2), 147-169.

Straub, E. T. (2009). Understanding technology adoption: theory and future directions for informal learning. Review of Educational Research, 79(2), 625-648.

Tremblay, D. (2002). Balancing work and family with telework? Organizational issues and challenges for women and managers. Women in Management Review, 17(3/4), 157170.

Veiga, J. F., Floyd, S., \& Dechant, K. (2001). Towards modelling the effects of national culture on IT implementation and acceptance. Journal of Information Technology, 16(3), 145-158.

Watad, M. M., \& Will, P. C. (2003). Telecommuting and organizational change: A middlemanagers' perspective. Business Process Management Journal, 9(4), 459-472.

Watson, K. J., Blackstone, J. H., \& Gardiner, S. C. (2007). The evolution of a management philosophy: The theory of constraints. Journal of Operations Management, 25(2), 387-402. 


\section{Appendix A - Questionnaire}

\section{Please tell us about your organization:}

\section{Size of organization:}
$\square$ Small $(<20)$
Medium (20-49)
Large (50+)

2. Proportion of workforces involved in teleworking in your organization:
$\square 0 \%$
$1-5 \%$
$\square$ 6-10\%
$\square 11-20 \%$
$21-50 \%$
$50 \%+$

\section{Please indicate to what extent the statements below are applicable to telework in your organization:}

\section{Benefit}

\begin{tabular}{|c|c|c|c|c|c|}
\hline & Not at all & Unlikely & Undecided & Likely & Definitely \\
\hline Telework increases productivity & $\square$ & $\square$ & $\bar{E}$ & $\bar{E}$ & $\square$ \\
\hline Telework provides more recruitment options & 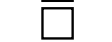 & 1 & 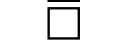 & 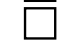 & 7 \\
\hline Telework reduce real estate expense & & & 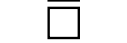 & $\square$ & 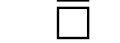 \\
\hline Benefits of telework gives competitive advantage & $\square$ & $\square$ & $\square$ & $\square$ & $\bar{\square}$ \\
\hline
\end{tabular}

\section{Top management support}

\begin{tabular}{|c|c|c|c|c|c|}
\hline & Not at all & Unlikely & Undecided & Likely & Definitely \\
\hline Top management is committed to teleworl & $\square$ & $\square$ & $\square$ & $\square$ & $\square$ \\
\hline
\end{tabular}

\section{Economic constraint}

\begin{tabular}{|c|c|c|c|c|c|}
\hline 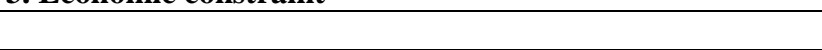 & Not at all & Unlikely & Undecided & Likely & Definitely \\
\hline $\begin{array}{l}\text { Hardware, software and infrastructure expenses for telework } \\
\text { are significant }\end{array}$ & $\square$ & $\square$ & $\square$ & $\square$ & $\square$ \\
\hline Changing the administrative system for teleworking is costly & $\square$ & $\square$ & $\square$ & $\square$ & $\square$ \\
\hline
\end{tabular}

\section{Workplace constraint}

\begin{tabular}{|c|c|c|c|c|c|}
\hline & Not at all & Unlikely & Undecided & Likely & Definitely \\
\hline $\begin{array}{l}\text { Losing one person in a small office because of teleworking } \\
\text { would be a problem for us }\end{array}$ & $\square$ & $\square$ & $\square$ & $\square$ & $\square$ \\
\hline $\begin{array}{l}\text { The telework program requires the organizational culture to } \\
\text { change }\end{array}$ & $\square$ & $\square$ & $\square$ & $\square$ & $\square$ \\
\hline Telework hinders teamwork & $\square$ & 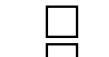 & $\square$ & $\square$ & $\square$ \\
\hline Managers lack trust in teleworkers & & & & $\square$ & \\
\hline Managing absent workers is difficult & $\square$ & $\square$ & $\square$ & $\square$ & $\square$ \\
\hline
\end{tabular}

\section{Technology constraint}

\begin{tabular}{|c|c|c|c|c|c|}
\hline & Not at all & Unlikely & Undecided & Likely & Definitely \\
\hline $\begin{array}{l}\text { Our current telecommunication technology supports working } \\
\text { at home }\end{array}$ & & & & & \\
\hline $\begin{array}{l}\text { Our company has appropriate infrastructure } \\
\text { Telework requires too much IT support }\end{array}$ & & & & $\square$ & L \\
\hline
\end{tabular}

\section{Risk}

Sensitive information can be lost though teleworking Telework creates problems with working hours and overtime pay rate

It is hard to ensure the safety and health of teleworkers

\section{Workforce constraint}

Our organization has tasks that are suitable for teleworking Existing employees are suitable for teleworking

$\begin{array}{ccccc}\text { Not at all } & \text { Unlikely } & \text { Undecided } & \text { Likely } & \text { Definitely } \\ \square & \square & \square & \square & \square \\ \square & \square & \square & \square & \square \\ \square & \square & \square & \square & \square \\ \square & \square & \square & \square & \square \\ \square & \square & \square & \square & \square\end{array}$


Employees like to do telework

8. Overall, what do you think are the main concerns regarding telework in your organization? $\square$ No real benefit

$\square$ Lack of top management support

$\square$ Economic constraints

Workplace constraints

$\square$ Technology constraints

$\square$ Risk

Workforce constraints

$\square$ Other (please specify):

Additional thoughts or comments 